\title{
The Typical Practice, Main Characteristics and Useful Reference of Community Informatics in the US
}

\author{
Xin Huang \\ Weifang University Library, Weifang 261061, China \\ Wfhx1966@163.com
}

Keywords: community and community informatics, information and communication technology, library and Information Science

\begin{abstract}
Community informatics is a new field of research, and social informatics education and development programs in the United States have achieved great results. This paper first introduces the meaning, main contents and main methods of community informatics, then expounds the typical practice of community informatics in the United States, emphatically describes the personnel training and scientific research projects in the direction of "community informatics" in some American universities, and then analyzes its main features, finally reveals the progress of community informatics in the United States, which provides useful reference for our country.
\end{abstract}

Community Informatics (CI) is a new field of research on the effective and widespread use of information and communication technology in communities and how to use it to promote community development. With the rapid development of computer network technology, community informatics emerged quietly in North America in the 1980s, and gradually became an independent discipline in the late 1990s. It has been rapidly developed and widely used in North America, Europe, Australia and other places. Community informatics involves library and information science, computer science, sociology and other disciplines, and has strong practicality. CI, as a new research field, is of great significance to improve the discipline system of Library and information science and other related disciplines and promote their long-term development; the methodology theory and practice of community informatics have great social value for the construction of community information system and the effective implementation of service projects in the community. Social informatics education and development projects in the United States have achieved great results; this paper focuses on the typical practice of community informatics in the United States, the main features and reference significance for China.

\section{Rational understanding of Community Informatics}

\subsection{The meaning of Community Information Science (CI)}

Community Informatics is also translated into Community Informatics, commonly referred to as CI. Many foreign scholars have expounded and defined community informatics from different 
perspectives, such as: Mike Gerstein [1], David Buljoya [2], Nancy Campbell [3]. To sum up, the meaning of community informatics (CI) can be defined as: community informatics is a new subject which mainly studies how to use information and communication technology to promote community development; CI emphasizes the practice of narrowing the digital divide, explores the formation and sharing of community information and knowledge, and pays attention to information and communication technology. The interaction and balance with the community, and the use of information and communication technology to achieve the basic rights of citizens [4]. Community Informatics is a subject with strong application, its meaning is constantly updated with the development of modern information network and communication technology.

\subsection{Main contents of Community Information Science (CI)}

It can be seen from the meaning of community informatics that CI focuses on the application of information and communication technology in the community, including community resource security, user training, information system design and technical maintenance, promotion and protection of local interests of the community, and highlights information and communication technology in community memory, community information. In short, the main contents of community informatics include the sustainable development of CI action, the social inclusiveness of $\mathrm{CI}$, the effective use of information and communication technology in the community and the absorptive capacity of the community.

\subsection{Main methods of Community Informatics (CI)}

Community informatics has a strong intersection and practicality. It has absorbed multidisciplinary research methods around the application and popularization of information and communication technology in the community. Hu Liyun, a scholar, thinks that community informatics has gradually formed three main methods in practice: community analysis, participatory method and community memory record. They are often used in a comprehensive way: community analysis can help to discover the excellent traditional culture of the community in the process of community memory record, and locate the community related to cultural resources in time. Members; Participatory methods can make the results of community analysis more fully reflect the characteristics and significance of the community; community memory records themselves are highly community-inclusive, inseparable from participatory methods, and provide a wealth of material for community analysis and further access to research subjects [6].

\section{Typical practice and main characteristics of American Community Informatics}

\subsection{Typical practice cases}

\subsubsection{University of Michigan School of Information's "Community Informatics" Direction of Ph.D. and Master's Education and Community Information Society}

The University of Michigan's School of Information has set up a "Community Informatics" program to train Ph.D. and Master's degree professionals in the application of ICT to community public service; graduates can be engaged in community responsibility management in such areas as community networks, community administration and the use of ICT to promote community development. Management, community network management, community digital media management and electronic community construction management. In addition to 48 credits required by the public to obtain a master's degree, 12 credits from the designated courses are required to 
qualify for graduation defense; these courses related to community informatics include: e-community, community information group forum, practical participation, and so on. Information Utilization in Communities, Community Information: Knowledge and Skills, Geographic Information System, Urban Network, etc. The University of Michigan's School of Information has also set up a community information community, a specialized research institute for community informatics, which provides a platform for academic exchanges between graduate students, teachers, alumni and social figures to explore the changing role of information and technology in civil society. Through community information societies, graduate students and tutors can participate in research projects and carry out discussions, which greatly enhance the students'hands-on ability and practical ability.

\subsubsection{Master's Training and Teaching Research Center in Community Informatics, Graduate School of Library and Information, University of Illinois, Urbara-Champaign}

The University of Illinois at Urbara-Champaign is one of the most important teaching and research centers in community informatics in the United States. Master's degree students in this research field are required to specialize in three courses of community informatics in the Master's degree program in Library science, totaling 12 credits. The training program provides core courses and related courses in the direction of community informatics. The main course is Community Informatics, which is compulsory for every student. It covers four credits. It mainly discusses how the community acquires, organizes, creates and shares information by using information and communication technology, and how libraries or other public sectors master it. The key principles of new technology and new media. In addition, at least two compulsory courses should be selected in the following courses: Community Participation, Social Science Research Methods in Library and Information Science, Digital Divide: Policy, Research and Community Empowerment, Community Information System, School and Community Child Services, Inquiry-based Learning, etc. Relevant courses in the direction of community informatics such as Community Archives, Technical Scientific Research: Discussion on Identity, Culture and Democracy, Population Informatics, etc. The University of Illinois, Urbara-Champaign, Graduate School of Library and Information Studies, a master's degree in community informatics, has one of the most important highlights: paying special attention to the cultivation of students'extracurricular practical ability, allowing students to participate in the information services of various communities and public welfare organizations; building and innovating community technologies with teachers and community members The center network and related software highlight students' ability building. At the same time, the College provides various opportunities for students to practice in urban community network centers, rural communities and immigrant communities, to understand the real situation of community needs and technology development, and to increase the potential for students to connect with the community [9]. In this way, the way and scope of graduates' employment are relatively extensive. Another bright spot is that the College has set up a teaching and Research Center for community informatics, which promotes knowledge creation and technology application in the field of community information research mainly through research and development, provides research, learning and practice bases for teachers and students, and strives to make it a national community information research activity heart [10].

\subsubsection{Cyber Navigator (CN) launched by the Chicago Public Library Foundation in collaboration with AT\&T}

Founded in 1986, the Chicago Public Library Foundation is an independent, non-profit educational organization that works with the government and the business community to enrich the 
collection and practice of the Chicago Public Library. In 1998, the Chicago Public Library Foundation, in collaboration with AT\&T, launched the Virtual Navigator Program, which recruited 27 part-time college students from Chicago universities for systematic training in the summer of 1999, and provided free online training and technical support to readers in its 23 community branches. Its job responsibilities mainly include one-to-one information technology counseling, reader use of computers in the process of solving sudden technical problems and providing daily maintenance support for Librarians of computer networks. The purpose of the Virtual Navigator Project is to provide professional guidance and help for adult and child readers to use the computer and digital information resources of public libraries, and to realize the mission of the Chicago Public Library to provide community readers with equal access to information. There are many direct beneficiaries of the Virtual Navigator Project, including children, adults and the elderly, ethnic minorities and librarians, and readers unfamiliar with computers and network technologies [11]. In view of the growing impact of the Virtual Navigator Project, the Community Informatics Laboratory of the Graduate School of Library and Information at the University of Illinois, Urbara-Champaign, dispatched research assistants to work with CNs in six of the project's branches to provide information and communication technology support services, and to develop and evaluate CNs and Community Informatics The study provides observation data.

\subsubsection{Other universities in the United States carry out "Community Informatics" teaching and research}

In the United States, there are many universities offering community informatics courses, such as Loyola University, University of Washington, University of South Florida, Texas Women's University, Pennsylvania State University, University of California, Berkeley and so on. Among them, Loyola University, located in Maryland, has set up a community informatics center; the School of Information Science and Technology of Pennsylvania State University has a dedicated team of teachers who study community informatics; and the School of Information of Washington University has actively participated in the organization of international conferences on community informatics [12]. In addition, the School of Arts and Sciences of the University of Toledo in the United States has established postgraduate programs in the field of social informatics. The focus of the postgraduate program is to study how to develop, manage and evaluate ICT in a community context, and how ICT interacts with various forms of communities [13].

\subsubsection{Community technology center network in the United States}

With the development and influence of community informatics, the United States has established a community informatics research and practice related institutional websites on the Internet, the more famous of which is the community technology center network. It is a national membership network of community technology centers in the United States, established to provide technical access and education to marginalized communities. The project provides members with a variety of community informatics resources, such as quarterly newsletters, relevant conference information and community technology center construction manual [14].

\subsection{Main features}

Through the above analysis, we can see that the related teaching and research of community informatics in the United States is in full swing: many colleges and universities of Library and information science or information institutes have set up "community informatics" courses; some universities have set up community informatics research centers which integrate teaching, scientific research and practice; and some schools have set up community informatics research centers. The 
school also has a doctorate and master's degree in community informatics. Among the typical practices of community informatics in the United States, the most important feature is the universal emphasis on the role of practice, the emphasis on "learning by doing" and the improvement in research. For example, the Graduate School of Library and Information at the University of Illinois, Urbara-Champaign, has set up a course called "Inquiry-based Learning", which advocates inquiry-based learning methods, puts forward the concept of "community inquiry" and applies it to the teaching and practice of community informatics, emphasizing case analysis and demonstration. It has a good effect. The various community informatics practice and research projects implemented in Universities in the United States have laid a solid foundation for their teaching; the projects themselves involve a large number of students in their practice. These long-lasting and wide-ranging projects provide a good teaching practice platform for community informatics education and research in the United States.

\section{The progress of American community informatics is beneficial to our country}

\subsection{China should pay attention to the education and research of community informatics}

The teaching and research management of community informatics in the United States are in good order, and various research projects on the application of information and communication technology to promote community development have been implemented. This point gives us useful lessons: our country should pay attention to the education and research of community informatics. Li Gang and other scholars believe that the theory and practice of American CI can be used for reference to the innovation and inclusive growth of social management in China. CI research can not only become the growth point of discipline development, but also provide a practical action plan for solving community problems in China. In recent years, institutions and government departments at all levels in China have launched information-rich peasants and information poverty alleviation projects, such as the national cultural information resources sharing project, the farmhouse bookstore project, etc., and a nationwide upsurge of actively developing digital countryside and urban construction and community informatization construction has been set off. After the basic layout of grass-roots units nationwide is basically completed, the construction and deepening of various projects at the community level will become the key to the next step of development. China can draw lessons from the successful practices of community informatics in the United States, vigorously carry out community informatics education and research; by introducing information and communication technology into the context of communities, focusing on community multicultural interaction, community mobilization, information literacy of community members, social inclusion of vulnerable groups and so on. In addition, as a new research field, community informatics is gradually being incorporated into or absorbed into the discipline system of Library and information science. Therefore, from the point of view of our library circles, strengthening the education and research of community informatics is conducive to the completion and development of the discipline system of Library and information.

\subsection{Special emphasis should be placed on the cultivation of practical ability in community informatics}

The United States attaches great importance to the strengthening and cultivation of practical ability in the teaching and research of community informatics, which also gives us inspiration. CI attaches importance to empirical methods such as participation, case studies and research. Maintaining the characteristics of combining academic research with community practice, 
developing community information and communication technology projects is the best way to cut into the research and practice of community informatics. Great progress has been made in the construction of urban community information system, regional information network and community information service in China. However, these practical experiences and research results are scattered in different disciplines and have not yet been systematically exchanged and integrated. Therefore, it is very important and urgent to draw lessons from the successful experience of community informatics abroad, attach importance to and strengthen the practical ability of community informatics, and build and improve a harmonious community.

\section{References}

[1] Gurstein M. What is community information (why does it matter?). Milan: Polimetrica, 2007 (11): 36-37.

[2] Bourgeois D T, Horan TA.A design theory approach to community information: Community-centered development and action research testing of online social networking prototype [EB/OL] [2012-08-28]. http://cijournal.net/index.php/ciej/article/viewPDFInterstitial/308/333.

[3] Campbell N D, Eubanks V. Community informatics as a pathway to social change [EB/OL] [2012-08-28]. http://www.brillomag.net/COPC/CI/.

[4] Yan Hui. Community Informatics: A New Field of Concern [J]. Library and Information Work, 2010, 54 (4): 53-55, 99.

[5] 15 Li Gang et al. Promoting Social Inclusion: A Review of American Community Informatics [J]. Journal of Chinese Library, 2012 (3): 64-68.

[6] Hu Li Yun. The main method of community informatics [J]. library and information work, 2012,56 (2): 10-13.

[7] Community Information related courses [EB/OL] [2012-08-28]. http://cic.si.umich.edu/blogs/seramard-courses.

[8] Community Information Initiative-University of Illinois at Urbana-Champaign [EB/OL] [2012-08-28]. http://cic.si.umichl.edu/.

[9] Certificate in Community Information [EB/OL] [2012-08-28].

http://www.lis.illinois.edu/academics/programs/ms/cii.

[10] The Community Informatics Initiative (CII) [EB/OL]. [2012-08-28]. http://www.cii.uiuc.edu/.

[11] Gurstein M.Is there a wireless community information?[J].Journal of Community Information, 2008, 4(1): 2-6.

[12] Information School, University of Washington [EB/OL]. [2012-08-28]. http://ishool.uw.edu/.

[13] Hu Liyun, 13-14. Professional education and research status of overseas community informatics [J]. Journal of University Library, 2011 (6): 11-18. 